\title{
Extracellular Matrix in Preterm Premature Rupture of Fetal Membranes
}

\author{
Chu Chu ${ }^{1,2}$, Elizabeth A Bonney ${ }^{3}$ and Nanbert Zhong ${ }^{1,3 *}$ \\ ${ }^{1}$ New York State Institute for Basic Research in Developmental Disabilities, USA \\ ${ }^{2}$ Lianyungang Maternal and Child Health Hospital, China \\ ${ }^{3}$ Department of Obstetrics and Gynecology, University of Vermont College of Medicine, USA
}

*Corresponding author: Nanbert Zhong, New York State Institute for Basic Research in Developmental Disabilities, 1050 Forest Hill Road, Staten Island, NY 10314, USA, Tel: (718) 494 5242; Fax: 4882

To Cite This Article: Chu Chu, Elizabeth A Bonney, Nanbert Zhong. Extracellular Matrix in Preterm Premature Rupture of Fetal Membranes. Am J Biomed Sci \& Res. 2021 - 13(1). AJBSR.MS.ID.001831. DOI: 10.34297/AJBSR.2021.13.001831.

Received: 眥 May 12, 2021; Published: 眥 June 01, 2021

\begin{abstract}
Spontaneous preterm birth (sPTB) is a complex health problem that is at the center of intense international collaboration. Detailed understanding of this syndrome is critical to improve related maternal, fetal, newborn health outcomes worldwide. Clinically, the antecedents of sPTB include spontaneous preterm labor (sPTL) or preterm premature rupture of membranes (pPROM), which accounts for one-third of sPTB. The integrity of the amniochorionic membrane is dependent on the extracellular matrix (ECM), which plays a significant role in the function of amnion epithelial cells and the tissue as a whole. ECM proteins mainly include fibronectin, total fibrilar collagens, proteoglycans, hyaluronan, desmoplasia, biglycan and decorin. Abnormalities in the ECM have been related to PPROM, but this link deserves further investigation. In this review, we briefly summarize the components of the ECM, ECM proteins, the functional pathways involving ECM proteins, and their potential role in the pathophysiology of pPROM.
\end{abstract}

Keywords: Extracellular matrix; Cell adhesion; Preterm birth

\section{Introduction}

Preterm birth (PTB) refers to live birth that occurs before 37 completed weeks of gestation. PTB is the principal cause of perinatal mortality and morbidity and the most common cause of death in children under 5 years old. PTB includes spontaneous preterm birth (sPTB) and indicated preterm birth (iPTB) in which birth is induced by medical reasons, such as intrauterine growth restriction, pre-eclampsia or fetal distress. SPTB may follow preterm labor (PTL) and subsequent membrane rupture and expulsion of the intrauterine contents. SPTB may also follow preterm premature rupture of fetal membranes (pPROM), which then leads in turn to labor and preterm birth. A portion of women with pPROM have labor induced for indication, including overt infection or fetal distress. Thus pPROM may lead to PTB along spontaneous and "indicated" pathways (e.g, GM-CSF, TNF- $\alpha$, TGF- $\beta$, IL-1 $\beta$, IL-6, IL-8, IL-10, etc.) [1].
The primary structure of the fetal membranes is the amnion composed of a monolayer epithelial cells, the basal (bottom, inner) border of which are in contact with amniotic fluid and at the apical (top, outer) border, a fundamentally collagen-rich layer of mesenchymal cells connected in turn to chorion [2]. The primary source of matrix and collagen support for the amnion is the mesenchymal cell layer. The elasticity, integrity and strength of fetal membranes is influenced by mesenchymal extracellular matrix (ECM) proteins and plays an essential role in preventing in pPROM. Dynamic changes of ECM can result in alterations in the components of the stroma, which sequentially affect cellular function mediated via membrane receptors that distinguish specific ECM composition [3]. The unique properties of major ECM proteins also affect the stability of ECM itself. These properties may be a factor not only in pPROM but also disfunction in other intrauterine 
environments that lead to, for example, abnormal placentation or cervical insufficiency [4-6]. The catabolism and synthesis of ECM are strictly controlled by cytokines and growth factors, as well as via expression of chaperone proteins, and the function of proteolytic enzymes activators and inhibitors [7-9]. This review describes recent development in the study of ECM metabolism and structure that are relevant to the process of physiological and pathological parturitions.

\section{ECM Composition and Structure}

ECM proteins comprise the NC1 domains of basement membrane collagen IV and the C-terminal domains of fibril-forming collagens [10]. Collagen is a plentiful structural protein in humans. It's the most abundant of the ECM, accounts for 3/4 dry weight of skin, comprises $1 / 3$ the total protein. Many proteins include collagenous domains [11,12]. The fibrillin microfibril, along with elastin is present in the elastic fiber. The fibrillin microfibril is a key component of the tissue homeostasis sequestering and storing the potential forms of members of the BMP family and TGF- $\beta$ [13-15]. Elastic fibers play key role in many tissues including lungs, skin, ligaments and arteries [16-18]. Tumor desmoplasia (fibrosis) is principally constituted of fibrillar collagens, secreted by both coopted cancer associated fibroblasts (CAFs) and cancer cells into the extracellular space. The desmoplasia decreases vascularity, increases tissue stiffs, and characteristically creates a physical encapsulation in and around the tumor. This fibrosis raises tumor metastasis and growth by activation of intracellular signaling networks at the molecular level [19].

ECM components are frequently oligomeric and large multidomain molecules [20]. The non-collagenous composition of the ECM includes proteoglycans, fibronectin, laminin, decorin, biglycan, hyaluronan, fibrinogen, plasminogen, and integrins [2123]. Progeoglycans (PGs) are a common component and the key constituents of ECM $[24,25]$. These proteins also attach to the lipid membrane of the cell and interact with many morphological factors, proteins and receptors from the ECM. They mediate a variety of biological reactions such as cell adhesion, proliferation, migration and differentiation [26]. Proteoglycans exist on nearly all animal cell surfaces to maintain cell adhesion [27].

Fibronectin (FN) is a $230 \sim 270 \mathrm{kDa}$ glycoprotein that is present in most ECM. The single FN gene transcript encodes 20 isoforms in humans. FN exists as a protein dimer consisting of two antiparallel monomers covalently bonded at their C-termini by a pair of disulfide bonds [28]. FN is comprised of repeating type I, II, III units. FN domains or units mediate ligand binding and selfassembly for gelatin/collagen, heparin, fibronectin, integrins, and other extracellular molecules [29]. FN is extensively expressed in embryos as well as adults, especially in areas of cell migration, active morphogenesis and inflammation.

Laminin is a $500-800 \mathrm{kDa}$ heterotrimeric glycoprotein located in the basement membrane. The sixteen trimeric isoforms which have been found in human and mouse tissues show both cell and tissue specificity [30-32]. Laminins contribute to the ECM structure and contribute to cellular differentiation, adhesion, phenotype stability, resistance to apoptosis, and migration.

Decorin is an ECM proteoglycan that contains a single-chain aminopoly saccharide and a core protein [33,34]. It is an archetypal Small Leucine Rich Proteoglycans (SLRP) structurally composing of single glycosaminoglycan (GAG) chain, either dermatan sulfate (CS) or chondroitin sulfate (DS), which is connection with the N-terminal of core protein [35]. It is secreted in the ECM by stromal cells like endothelial, myofibroblast and fibroblast [35]. Decorin is a natural ligand for insulin like growth factor-1R (IGF-1R), receptor tyrosine kinase especially epidermal growth factor receptor (EGFR), c-met (hepatocyte growth factor receptor (HGFR)), fibroblast growth receptor (FGFR), transforming growth factor- $\beta$ (TGF- $\beta$ ), toll like receptors (TLR) [35-37]. Decorin makes receptor tyrosine kinase c-met inactivate and lead to inhibition of downstream $\beta$-catenin signaling which reduces cancer metastasis [38]. Biglycan, a $42 \mathrm{kDa}$ core protein, is class I SLRP that is similar structure with decorin [39]. It is broadly expressed in ECM where it plays an important role as an essential signaling molecule and a key matrix component [39]. Biglycan mediates TLR activation and consequent NF-kB expression to influence cancer migration. Recombinant Biglycan has revealed to prompt gastric cancer cell migration by TLR- NFKB-HIF-1 $\alpha$-VEGF mediated axis [40].

Hyaluronan (HA) is a ubiquitously expressed glycosaminoglycan. Although HA structure is simple, with repeating glucuronic acid and disaccharide chains of $\mathrm{N}$-acety1-Glucosamine, its biology is wonderfully complex $[41,42]$. HA plays an essential role in approximately all areas of biology. Its interactions with extracellular binding partners or cell receptors are important in cell and organ development and, the cellular response to migratory signals, tissue inflammation and injury, cancer formation and resistance of cancer [43-45].

Fibrinogen is a $340-\mathrm{kDa}$ fibrous glycoprotein made up of $\sim 3000$ amino acids. Two pairs of three-peptide (alpha, beta, gamma) molecular units connected by five symmetric disulfide bridges comprise the structure of this molecule [46], which depends on bound calcium for its structure and function.

The plasminogen activator system includes binding proteins, a proteolytic cascade of serine proteases and active broad-spectrum serine protease plasmin of inhibitors which control the spatial and 
temporal generation [47]. The physiological roles of this system includes ECM degradation, fibrinolysis, cell signaling, and wound healing [48]. The plasminogen and associated proteins contribute to inflammation, and there has been a recent focus on the role that plasminogen has in the development, progression, and regulation of diseases with an inflammation component.

The integrin family of type I transmembrane adhesion receptors are principally responsible for mediating cell-matrix attachments, but integrins can also be participated in cell adhesion, signaling and migration in disease and health [49-51]. Integrins play key roles in epithelial cells. Integrins in epithelial cells have been confirmed to vital components of the signaling that serves to both establish and control epithelial adhesion to the basement membrane [52]. Integrins are adhesion receptors which mediate communication between the intracellular and extracellular environments and are vital for universal tissue.

\section{ECM Structural Components of the Fetal Membrane}

Collagen is the main structural component of fetal membrane ECM [53] and the distribution of ECM collagen types, includingI, III, IV, Vand VI, has been examined by immunohistochemistry [21]. The key component of fetal membrane ECM, type IV collagen, provides a holder for assembling other structural proteins for maintaining the tensile strength of fetal membranes. Types V and VII are minor fibrillar collagens, which afford an extra anchoring function for the basement membrane together with type IV collagen. Types VI and VII represent a small fraction of the collagen in the fetal membrane ECM. However, in conjunction with types Iand III, they form a critical anchoring fibrillar structure. The different types of fibrillar collagens (types, II, III, XXIV and XXVII) have different with their vulnerability to cleavage by matrix metalloproteinases (MMPs). MMPs participate in the action of physiological degradation and extracellular proteases [54]. Some MMPs family member have been found in the fetal membranes [55]. For example, type I collagen is less efficiently cleaved by MMP-1 than type III collagen [56,57] ECM proteins affect cell morphology behavior through signaling by cell surface receptors, mainly by MMPs [9]. The presence of specific memebrane ECM molecules is determined by the velocity of their synthesis and their degradation.

\section{ECM and Associated Signaling and Cytokine Expression Pathways}

Cells can sense ECM stiffening via integrins through cytoskeletal filaments that induce changes within the cell and manage cell migration. So, stiffer ECM can provoke manufacture of heparin sulfate proteoglycans, fibrin and from the other side to integrins, fibronectin as a glycoprotein of the ECM binding from one side to extracellular collagen [58]. ECM stiffening can also enhance cytoskeletal tension by Rho/ROCK signaling activation and increase cell-ECM adhesion connecting the ECM to the cytoskeleton by local adhesion proteins $[59,60]$. Fork head box $\mathrm{O}$ (FoxO) proteins regulate ECM remodeling, inflammation and apoptosis. Fox01, FoxO3, and FoxO4 belong to the FoxO subfamily of Forkhead transcription factors [61]. These related subfamily members are vital physiologic targets of protein kinase B (PKB)/phoshpatidylinositol-3 kinase (PI3K) signaling [62,63]. PI3K signaling can influence matrix stiffness and cell movement by integrin-mediated activation of FAK [64]. FoxO3 can reduce tissue inhibitor of MMP1 in human umbilical vein endothelial cells and induce MMP-3, MMP-9 and MMP-13 activity and expression in cancer cells $[65,66]$.

cytokines regulate MMP expression in fetal membranes. Research studies suggested that the pro-inflammatory cytokine TNF- $\alpha$ can activate the c-Jun N -terminal kinases (JNK) stress signaling pathway and, in turn, help nuclear import and subsequent activation of Fox04 thus leading to the enhancement of MMP-9 gene transcription and enzymatic activity $[67,68]$. In contrast, in vitro studies with amnion cells showed that either tumor

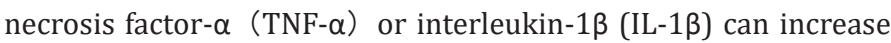
secretion of the MMP-9 proenzyme but not activation [69]. TNF- $\alpha$ binding to its receptor can activate caspases, degradation of ECM, and apoptosis in fetal membranes, which in turn promotes pPROM [70]. An increase expression of MMP-2 and MMP-9, and a decrease of expression of tissue inhibitors of TIMP-1 and TIMP2 can increase the risk of pPROM. This is likely important as some studies have shown that the overexpression of MMP-1 and MMP-9 can be mediated by IL- $1 \beta$ release from activated macrophages. An important cellular source of prostaglandins (PGs) in intrauterine tissues is the amnion [71]. PG, by upregulating MMP-9, also may participate in membrane rupture [72]. MMP-9 is likely a critical mediator in degradation of the ECM of fetal membranes in normal parturition [73]. MMP-9 preferentially targets basement membrane elastin, collagen (collagen IV), and fibronectin [74,75] and may also participate in fetal membrane rupture through degradation of type IV collagen. I

L-1 $\beta$ is usually undetected in amniotic fluid during normal pregnancy, while IL-1 $\beta$ levels in amniotic fluid in preterm birth with and without infection is range from 100 to $2000 \mathrm{pg} / \mathrm{ml}[76$, 77]. IL-1 $\beta$ plays a key role in inducing expression of MMP-9 in amniochorion in response to lipopolysaccharide (LPS) stimulation [78]. Further, LPS provokes immune system cells via binding cellsurface Toll-like receptor 4 (TLR4) and activating protein kinase, such as p38 kinase and NF- $\mathrm{kB}$, leading to an overexpression of proinflammatory cytokines, increased production of matrix-degrading enzymes and adhesion molecules [79]. TLR4 is generally expressed via the fetal membranes, placental trophoblasts and the female 
reproductive tract [80-82]. In some cases, elevated levels of MMP-8 are thought to be the result of increased proinflammatory cytokine IL-6 in the context of infection-induced inflammation [83,84]. In other cases of such inflammation, the observed increase in intraamniotic lactic acid in the amniotic membrane suggests that an increase in anaerobic glycolysis may raise the production of MMP8 thus weakening the maternal membrane [85]. However, the association between MMP-8 and IL-6 levels was unclear [85].

\section{Pathophysiological Role of ECM in pPROM}

Degradation of amniotic membrane ECM components, structural alterations in ECM and resulting biomechanical changes in the membranes [6] are hypothesized to participate in the pathway leading to membrane rupture at term and in pPROM. In addition, anomalous disruption of the ECM at the trophoblast layer may relate to a regional thinning or absence of decidua and an increase in trophoblast apoptosis [86-88]. Down regulation of ECM-receptor interactions has also been documented [89]. Several lines of evidence suggest a direct relationship between infection or inflammation and pPROM. This evidence includes the increased expression or activity of inflammatory mediators such as IL-1 $\beta$, IL-2, IL-6, IL-12, IL-18, TNF- $\alpha$, interferon $\gamma$ (IFN $\gamma$ ), epidermal growth factor (EGF), C-reactive protein (CRP), soluble intercellular adhesion molecule I (ICAM-I) in pPROM [90-99]. It is likely that these molecules work participating in pathways and leading to disruption of ECM protein interactions.

\section{Epigenetic Regulation of Long non-coding RNAs on the ECM in pPROM}

Long non-coding RNAs (IncRNAs) are long single-stranded RNAs with no translational potential. LncRNAs function in regulating epigenetic and cellular processes through various mechanisms. By analyzing the present available studies of IncRNA transcripts within the reproductive system and the current understanding of the biology of IncRNAs, the important diagnostic and therapeutic roles of IncRNAs in the etiology of reproductive disorders have been illustrated [100]. LncRNA is a mediator of the outcomes of interaction at the maternal-fetal interface and in the biological mechanisms underlying trophoblast differentiation [101,102]. In addition to miscarriage, intrauterine grown retardation, preeclampsia, and gestational diabetes mellitus [103,104], a pathogenic role for IncRNA has been observed in human SPTB, wherein the epigenetic regulatory function of IncRNA was found to link social and environmental exposures and the outcome of pregnancy $[105,106]$. Down-regulation of lncRNAs on laminin, collagens, VLA $\alpha 10,0 P N, \alpha 6 \beta 1$, and $\alpha / \beta D G$, which also implied that these lncRNAs may be significant for the decreased synthesis of mRNA and leaded to weakening of the ECM. Several co-differentially expressed pairs of IncRNA-mRNA sharing the same genomic loci in SPTB were recognized as being associated with the infectioninflammation pathway and ubiquitine-proteasome system [107].

\section{Conclusion}

The above experimental and clinical data have identified the causal nature of intrauterine infection and cervix vaginal infection in explaining the progress of sPTB and pPROM. The inflammatory response can lead to the activation of mechanisms and resulting in labour. But in some cases, pregnancy with the infection can maintain to term without complications. In other cases, the major event is activation of myometrial movement, leading to the risk of sPTB. In other cases, the primary outcome is the secretion of MMP from fetal membranes, resulting in pPROM. Therefore, a better understanding of the relationship between the ECM and the pPROM remains limited and is elucidated to shed light on effective strategies to provide opportunities to prevent the potential risk of pPROM during pregnancy.

\section{Conflict of Interest}

No conflict of interest declared.

\section{Acknowledgement}

This study is supported in part by the New York State Research Foundation for Mental Hygiene (914-3280, 914-3257), and the National Institutes of Health (R01 HD094381)..

\section{References}

1. Liu L, Oza S, Hogan D, Perin J, Rudan I, et al. (2015) Global, regional, and national causes of child mortality in 2000-13, with projections to inform post-2015 priorities: an updated systematic analysis. Lancet 385(9966): 430-440.

2. Oyen ML, Calvin SE, Landers DV (2006) Premature rupture of the fetal membranes: is the amnion the major determinant? Am J Obstet Gynecol 195(2): 510-515.

3. Egeblad M, Rasch MG, Weaver VM (2010) Dynamic interplay between the collagen scaffold and tumor evolution. Curr Opin Cell Biol 22(5): 697-706.

4. Whitley GS, Cartwright JE (2010) Cellular and molecular regulation of spiral artery remodelling: lessons from the cardiovascular field. Placenta 31(6): 465-474.

5. Timmons B, Akins M, Mahendroo M (2010) Cervical remodeling during pregnancy and parturition. Trends Endocrinol Metab 21(6): 353-361.

6. Mercer BM (2011) Preterm premature rupture of the membranes. Obstet Gynecol 101(1): 178-193.

7. Clark IM, Swingler TE, Sampieri CL, Edwards DR (2008) The regulation of matrix metalloproteinases and their inhibitors. Int J Biochem Cell Biol 40(6-7): 1362-1378.

8. Hynes RO (2009) The extracellular matrix: not just pretty fibrils. Science 326(5957): 1216-1219.

9. Ricard-Blum S, Ballut L (2011) Matricryptins derived from collagens and proteoglycans. Front Biosci 16: 674-697.

10. Engel J, Hans Peter B (2005) Structure, stability and folding of the collagen triple helix. Top Curr Chem 247: 7-33. 
11. Brinckmann J (2005) Collagens at a Glance. Top Curr Chem 247: 1-6.

12. Veit G, Kobbe B, Keene DR, Paulsson M, Koch M, et al. (2005) Collagen XXVIII, a Novel von Willebrand Factor A Domain-containing Protein with Many Imperfections in the Collagenous domain. J Biol Chem 281(6): 3494-3504.

13. Neptune ER, Frischmeyer PA, Arking DE, Myers L, Bunton TE, et al. (2003) Dysregulation of TGF-|[beta]| activation contributes to pathogenesis in Marfan syndrome. Nat Genet 33(3): 407-411.

14. Kaartinen V, Warburton D (2003) Fibrillin controls TGF- $\beta$ activation. Nat Genet 33(3): 331-332.

15. Sengle G, Charbonneau NL, Ono RN, Sasaki T, Alvarez J, et al. (2008) Targeting of Bone Morphogenetic Protein Growth Factor Complexes to Fibrillin. J Biol Chem 283(20): 13874-13888.

16. Kielty CM, Sherratt MJ, Shuttleworth CA (2002) Elastic fibres. J Cell Sci 115 (Pt 14): 2817-2828.

17. Wright RR (1961) Elastic tissue of normal and emphysematous lungs. A tridimensional histologic study. Am J Pathol 39(3): 355-367.

18. Wagenseil JE, Mecham RP (2009) Vascular Extracellular Matrix and Arterial Mechanics. Physiol Rev 89(3): 957-989.

19. Hastings JF, Skhinas JN, Fey D, Croucher DR, Cox TR (2019) The extracellular matrix as a key regulator of intracellular signalling networks. Br J Pharmacol 176(1): 82-92.

20. Forslund K, Sonnhammer EL (2012) Evolution of protein domain architectures. Methods Mol Biol 856: 187-216.

21. Malak TM, Ockleford CD, Bell SC, Dalgleish R, Bright N, et al. (1993) Confocal immunofluorescence localization of collagen types I, III, IV, $\mathrm{V}$ and VI and their ultrastructural organization in term human fetal membranes. Placenta 14(4): 385-406.

22. Aplin JD, Campbell S, Allen TD (1985) The extracellular matrix of human amniotic epithelium: Ultrastructure, composition and deposition. J Cell Sci 79: 119-136.

23. Bryant-Greenwood GD (1998) The extracellular matrix of the human fetal membranes: Structure and function. Placenta 19(1): 1-11.

24. Iozzo RV (2005) Basement membrane proteoglycans: from cellar to ceiling. Nat Rev Mol Cell Biol 6(8): 646-656.

25. Kim SH, Turnbull J, Guimond S (2011) Extracellular matrix and cell signalling: the dynamic cooperation of integrin, proteoglycan and growth factor receptor. J Endocrinol 209(2): 139-151.

26. Bishop JR, Manuela S, Esko JD (2007) Heparan sulphate proteoglycans fine-tune mammalian physiology. Nature 446(7139): 1030-1037.

27. Culp LA, Murray BA, Rollins BJ (1979) Fibronectin and proteoglycans as determinants of cell-substratum adhesion. J Supramol Struct 11(3): 401-427.

28. Jahed Z, Shams H, Mehrbod M, Mofrad MR (2014) Mechanotransduction pathways linking the extracellular matrix to the nucleus. Int Rev Cell Mol Biol 310: 171-220.

29. Sabatier L, Chen D, Fagotto-Kaufmann C, Hubmacher D, McKee MD, et al. (2009) Fibrillin Assembly Requires Fibronectin. Mol Biol Cell 20(3): 846-858.

30. Miner JH, Yurchenco PD (2004) Laminin functions in tissue morphogenesis. Annu Rev Cell Dev Biol 20: 255-284.

31. Aumailley M, Bruckner-Tuderman L, Carter WG, Deutzmann R, Edgar D, et al. (2005) A simplified laminin nomenclature. Matrix Biol 24(5): 326332.

32. Domogatskaya A, Rodin S, Tryggvason K (2012) Functional Diversity of Laminins. Annu Rev Cell Dev Biol 28(1): 523-553.
33. Zhang W, Ge Y, Cheng Q, Zhang Q, Fang L, et al. (2015) Decorin is a pivotal effector in the extracellular matrix and tumour microenvironment. Oncotarget 9(4): 5480-5491.

34. Gubbiotti MA, Vallet SD, Ricard-Blum S, Iozzo RV (2016) Decorin interacting network: A comprehensive analysis of decorin-binding partners and their versatile functions. Matrix Biol 55: 7-21.

35. Neill T, Schaefer L, Iozzo RV (2012) Decorin. Am J Pathol 181(2): 380387.

36. Schaefer L, Iozzo RV (2008) Biological Functions of the Small Leucinerich Proteoglycans: From Genetics to Signa transduction. J Biol Chem 283(31): 21305-21309.

37. Neill T, Schaefer L, Iozzo RV (2016) Decorin as a multivalent therapeutic agent against cancer. Adv Drug Deliv Rev 97: 174-185.

38. Buraschi S, Pal N, Tyler-Rubinstein N, Owens RT, Neill T, et al. (2010) Decorin antagonizes Met receptor activity and down-regulates betacatenin and Myc levels. J Biol Chem 285(53): 42075-42085.

39. Nastase MV, Young MF, Schaefer L (2012) Biglycan: a multivalent proteoglycan providing structure and signals. J histochem Cytochem 60(12): 963-975

40. Hu L, Zang MD, Wang HX, Li JF, Su LP, et al. (2016) Biglycan stimulates VEGF expression in endothelial cells by activating the TLR signaling pathway. Mol Oncol 10(9): 1473-1484.

41. Wight TN (2017) Provisional matrix: A role for versican and hyaluronan. Matrix Biol 60: 38-56

42. Johnson P, Arif AA, Lee-Sayer SSM, Dong Y (2018) Hyaluronan and Its Interactions With Immune Cells in the Healthy and Inflamed Lung. Front Immunol 9: 2787.

43. Wight TN, Frevert CW, Debley JS, Reeves SR, Parks WC, et al. (2017) Interplay of extracellular matrix and leukocytes in lung inflammation. Cell Immunol 312: 1-14.

44. Nagyova E (2018) The Biological Role of Hyaluronan-Rich OocyteCumulus Extracellular Matrix in Female Reproduction Int J Mol Sci 19(1): 283.

45. Zhang X, Sun D, Song JW, Zullo J, Lipphardt M, et al. (2018) Endothelial cell dysfunction and glycocalyx - A vicious circle. Matrix Biol 71-72: 421431.

46. Mosesson MW (2005) Fibrinogen and fibrin structure and functions. J Thromb Haemost 3(8): 1894-1904.

47. Chana-Muñoz A, Jendroszek A, Sønnichsen M, Wang T, Ploug M, et al. (2019) Origin and diversification of the plasminogen activation system among chordates. BMC Evol Biol 19(1): 27.

48. Li WY, Chong SS, Huang EY, Tuan TL (2003) Plasminogen activator/ plasmin system: a major player in wound healing? Wound Repair Regen 11(4): 239-247

49. Sun Z, Costell M, Fässler R (2019) Integrin activation by talin, kindlin and mechanical forces. Nat Cell Biol 21(1): 25-31.

50. Moreno-Layseca P, Icha J, Hamidi H, Ivaska J (2019) Integrin trafficking in cells and tissues. Nat Cell Biol 21(2): 122-132.

51. Humphries JD, Chastney MR, Askari JA (2019) Signal transduction via integrin adhesion complexes. Curr Opin Cell Biol 56: 14-21.

52. Lee JL, Streuli CH (2014) Integrins and epithelial cell polarity. J Cell Sci 127(15): 3217-3225.

53. Kanayama N, Terao T, Kawashima Y, Horiuchi K, Fujimoto D (1985) Collagen types in normal and prematurely ruptured amniotic membranes. Am J Obstet Gynecol 153(8): 899-903. 
54. Cui N, Hu M, Khalil RA (2017) Biochemical and biological attributes of matrix metalloproteinases. Prog Mol Biol Transl Sci 147: 1-73.

55. Fujimoto T, Parry S, Urbanek M, Sammel M, Macones G, et al. (2002) A single nucleotide polymorphism in the matrix metalloproteinase-1 (MMP-1) promoter influences amnion cell MMP-1 expression and risk for preterm premature rupture of the fetal membranes. J Biol Chem 277(8): 6296-6302.

56. Shoulders MD, Raines RT (2009) Collagen structure and stability. Annu Rev Biochem 78: 929-958.

57. Gordon MK, Hahn RA (2010) Collagens. Cell Tissue Res 339(1): 247-257.

58. Gkretsi V, Stylianopoulos T (2018) Stylianopoulos, Cell adhesion and matrix stiffness: coordinating cancer cell invasion and metastasis. Front Oncol 8: 145

59. Paszek MJ, Zahir N, Johnson KR, Lakins JN, Rozenberg GI, et al. (2005) Tensional homeostasis and the malignant phenotype. Cancer Cell 8(3): 241-254.

60. Samuel MS, Lopez JI, McGhee EJ, Croft DR, Strachan D, et al. (2011) Actomyosin-Mediated Cellular Tension Drives Increased Tissue Stiffness and $\beta$-Catenin Activation to Induce Epidermal Hyperplasia and Tumor Growth. Cancer Cell 19(6): 776-791.

61. Anderson MJ, Viars CS, Czekay S (1998) Cloning and characterization of three human forkhead genes that comprise an FKHR-like gene subfamily. Genomics 47(2): 187-189.

62. Brunet A, Bonni A, Zigmond MJ, Lin MZ, Juo P, et al. (1999) Akt promotes cell survival by phosphorylating and inhibiting a forkhead transcription factor. Cell 96(6): 857-868.

63. Kops GJ, de Ruiter ND (1999) Direct control of the forkhead transcription factor AFX by protein kinase B. Nature 398: 6728.

64. Kallergi G, Agelaki S, Markomanolaki H, Georgoulias V (2007) Activation of FAK/PI3K/Rac1 signaling controls actin reorganization and inhibits cell motility in human cancer cells. Cell Physiol Biochem 20(6): 977-986.

65. Storz P, Döppler H, Copland JA, Simpson KJ, Toker A (2009) FOXO3a promotes tumor cell Invasion through the Induction of matrix metalloproteinases. Mol Cell Biol 29(18): 4906-4917.

66. Lee HY, You HJ, Won JY, Youn SW, Cho HJ, et al. (2008) Forkhead Factor, FOX03a, Induces Apoptosis of Endothelia Cells Through Activation of Matrix Metalloproteinases. Arterioscler Thromb Vasc Biol 28(2): $302-$ 308.

67. Li H, Liang J, Castrillon DH (2007) FoxO4 Regulates Tumor Necrosis Factor Alpha-Directed Smooth Muscle Cell Migration by Activating Matrix Metalloproteinase 9 Gene Transcription. Mol Cell Biol 27(7): 2676-2686.

68. Essers MA, Weijzen S, de Vries-Smits AM, Saarloos I, de Ruiter ND, et al. (2004) FOXO transcription factor activation by oxidative stress mediated by the small GTPase Ral and JNK. EMBO J 23(24): 4802-4812.

69. Fortunato SJ, Menon R, Lombardi SJ (1999) MMP/TIMP imbalance in amniotic fluid during PROM: an indirect support for endogenous pathway to membrane rupture. J Perinat Med 27(5): 362-368.

70. Menon R, Fortunato SJ (2007) Infection and the role of inflammation in preterm premature rupture of the membranes. Best Pract Res Clin Obstet Gynaecol 21(3): 467-478

71. Duchesne MJ, Thaler-Dao H, de Paulet AC (1978) Prostaglandin synthesis in human placenta and fetal membranes. Prostaglandins 15(1): 19-42.

72. McLaren J, Taylor DJ, Bell SC (2000) Prostaglandin E2-dependent production of latent matrix metalloproteinase- 9 in cultures of human fetal membranes. Mol Hum Reprod 6(11): 1033-1040.
73. Vadillo-Ortega F, González-Avila G, Furth EE, Lei H, Muschel RJ, et al. (1995) 92-kd type IV collagenase (matrix metalloproteinase-9 activity in human amniochorion increases with labor. Am J Pathol 146(1): 148156.

74. Senior RM, Griffin GL, Fliszar CJ, Shapiro SD, Goldberg GI, et al. (1991) Human 92- and 72-kilodalton type IV collagenases are elastases. J Biol Chem 266(12): 7870-7875.

75. Wilhelm SM, Collier IE, Marmer BL, Eisen AZ, Grant GA, et al. (1989) SV40-transformed human lung fibroblasts secrete a 92-kDa type IV collagenase which is identical to that secreted by normal human macrophages. J Biol Chem 264(29): 17213-17221.

76. Cox SM, Casey ML, MacDonald PC (1997) Accumulation of interleukin$1 \beta$ and interleukin- 6 in amniotic fluid: a sequela of labour at term and preterm. Hum Reprod Update 3(5): 517-527.

77. Hillier SL, Witkin SS, Krohn MA, Watts DH, Kiviat NB (1993) The relationship of amniotic fluid cytokines and preterm delivery, amniotic fluid infection, histologic chorioamnionitis, and chorioamnion infection. Obstet Gynecol 81(6): 941-948.

78. Arechavaleta-Velasco F, Ogando D, Parry S, Vadillo-Ortega F (2002) Production of matrix metalloproteinase-9 in lipopolysaccharidestimulated human amnion occurs through an autocrine and paracrine proinflammatory cytokine-dependent system. Biol Reprod 67(6): 1952 1958.

79. Manthey CL, Brandes ME, Perera PY, Vogel SN (1992) Taxol increases steady-state levels of lipopolysaccharide-inducible genes and proteintyrosine phosphorylation in murine macrophages. J Immunol 149(7): 2459-2465.

80. Gonzalez JM, Xu H, Ofori E, Elovitz MA (2007) Toll-like receptors in the uterus, cervix, and placenta: is pregnancy an immunosuppressed state? Am J Obstet Gynecol 197(3): 296.e1-296.e6.

81. Sheldon IM, Roberts MH (2010) Toll-Like Receptor 4 Mediates the Response of Epithelial and Stromal Cells to Lipopolysaccharide in the Endometrium. PLoS One 5(9): e12906.

82. Moço NP, Martin LF, Pereira AC, Polettini J, Peraçoli JC (2013) Gene expression and protein localization of TLR-1, -2, -4 and -6 in amniochorion membranes of pregnancies complicated by histologic chorioamnionitis. Eur J Obstet Gynecol Reprod Biol 171(1): 12-17.

83. Shim SS, Romero R, Hong JS, Park CW, Jun JK, et al. (2004) Clinical significance of intra-amniotic inflammation in patients with preterm premature rupture of membranes. Am J Obstet Gynecol 191(4): 13391345.

84. Angus SR, Segel SY, Hsu CD, Locksmith GJ, Clark P, et al. (2001) Amniotic fluid matrix metalloproteinase- 8 indicates intra-amniotic infection. Am J Obstet Gynecol 185(5): 1232-1238.

85. Belfort MA (2018) Predicting premature preterm rupture of the membranes after fetal surgery. BJOG 125(10): 1293.

86. Silaban B (2005) Analisis dan standarisasi buku kimia kelas XII semester 2 berdasarkan standar ISI KTSP. Biol Reprod 72(3): 720-726.

87. Elkhwad M, Pandey V, Stetzer B, Mercer BM, Kumar D, et al. (2006) Fetal Membranes From Term VAginal Deliveries have a Zone of Weakness Exhibiting Characteristics of Apoptosis and Remodeling. J Soc Gynecol Investig 13(3): 191-195.

88. Lappas M, Lim R, Riley C, Menon R (2010) Expression and localisation of FoxO3 and FoxO4 in human placenta and fetal membranes. Placenta 31(12): 1043-1050.

89. Luo X, Shi Q, Gu Y, Pan J, Hua M, et al. (2013) LncRNA pathway involved in premature preterm rupture of membrane (PPROM): an epigenomic 
approach to study the pathogenesis of reproductive disorders. PLoS One 8(11): e79897.

90. Zou L, Zhang H, Zhu J, Zhu J (2004) The value of the soluable intercellular adhesion molecule-1 levels in matermal serum for determination of occult chorioamnionitis in premature rupture of membranes. J Huazhong Univ Sci Technol Med Sci 24(2): 154-157.

91. Weiyuan Z, Li W (1998) Study of interleukin-6 and tumor necrosis factor-alpha levels in maternal serum and amniotic fluid of patients with premature rupture of membranes. J Perinat Med 26(6): 491-494.

92. Shobokshi A, Shaarawy M (2002) Maternal serum and amniotic fluid cytokines in patients with preterm premature rupture of membranes with and without intrauterine infection. Int J Gynaecol Obstet 79(3): 209-215.

93. Athayde N, Romero R, Maymon E, Gomez R, Pacora P, et al. (2000) Interleukin 16 in pregnancy, parturition, rupture of fetal membranes, and microbial invasion of the amniotic cavity. Am J Obstet Gynecol 182 (1 Pt 1): 135-141.

94. Saini S, Goel N, Sharma M, Arora B, Garg N (2003) C-reactive proteins as an indicator of sub-clinical infection in cases of premature rupture of membranes. Indian J Pathol Microbiol 46(3): 515-516.

95. Rizzo G, Capponi A, Vlachopoulou A, Angelini E, Grassi C, et al. (1998) Interleukin- 6 concentrations in cervical secretions in the prediction of intrauterine infection in preterm premature rupture of the membranes. Gynecol Obstet Invest 46(2): 91-95.

96. El-Shazly S, Makhseed M, Azizieh F, Raghupathy R (2004) Increased expression of pro-inflammatory cytokines in placentas of women undergoing spontaneous preterm delivery or premature rupture of membranes. Am J Reprod Immunol 52(1): 45-52.

97. Menon R, Lombardi SJ, Fortunato SJ (2001) IL-18, a product of choriodecidual cells, increases during premature rupture of membranes but fails to turn on the Fas-FasL-mediated apoptosis pathway. J Assist Reprod Genet 18(5): 276-284.
98. Romero R, Mazor M, Sepulveda W, Avila C, Copeland D, et al. (1992) Tumor necrosis factor in preterm and term labor. Am J Obstet Gynecol 166(5): 1576-1587.

99. Romero R, Manogue KR, Mitchell MD (1990) Infection and labor. IV. Cachectin-tumor necrosis factor in the amniotic fluid of women with intraamniotic infection and preterm labor. Am J Obstet Gynecol 161(2): 336-341.

100. Shen C, Zhong N (2015) Long non-coding RNAs: the epigenetic regulators involved in the pathogenesis of reproductive disorder. Am J Reprod Immunol 73(2): 95-108.

101. McAninch D, Roberts CT, Bianco-Miotto T (2017) Mechanistic Insight into Long Noncoding RNAs and the Placenta. Int J Mol Sci 18(7): 1371.

102. Zou Y, Jiang Z, Yu X, Sun M, Zhang Y, et al. (2013) Upregulation of long noncoding RNA SPRY4-IT1 modulates proliferation, migration, apoptosis, and network formation in trophoblast cells HTR-8SV/neo. PLoS One 8(11): e79598.

103. Sõber S, Reiman M, Kikas T, Rull K, Inno R, et al. (2015) Extensive shift in placental transcriptome profile in preeclampsia and placental origin of adverse pregnancy outcomes. Sci Rep 5: 13336.

104. He X, Ou C, Xiao Y, Han Q Li H, et al. (2017) LncRNAs: key players and novel insights into diabetes mellitus. Oncotarget 8(41): 71325-71341.

105. Romero R, Gómez R, Chaiworapongsa T, Conoscenti G, Kim JC, et al. (2001) The role of infection in preterm labour and delivery. Paediatr Perinat Epidemiol 15(Suppl 2): 41-56.

106. Romero R, Yoon BH, Mazor M, Gomez R, Diamond MP, et al. (1993) The diagnostic and prognostic value of amniotic fluid white blood cell count, glucose, interleukin-6, and gram stain in patients with preterm labor and intact membranes. Am J Obstet Gynecol 169(4): 805-816.

107. Zhao X, Dong X, Luo X, Pan J, Ju W, et al. (2017) Ubiquitin-ProteasomeCollagen (CUP) Pathway in Preterm Premature Rupture of Fetal Membranes. Front Pharmacol 8: 310. 